\title{
A AGRESSIVIDADE COMO ELEMENTO INTRíSECO DO DESENVOLVIMENTO EMOCIONAL NA TEORIA WINNICOTTIANA
}

\author{
Rafaela Reginato Hosokawa; Fabio Camargo Bandeira Villela \\ Universidade Estadual Paulista - UNESP, Faculdade de Ciências e Tecnologia - FCT, Departamento de Educação, \\ Presidente Prudente, SP. E-mail: rafaela_reginato@hotmail.com
}

\section{RESUMO}

Este artigo versa sobre a concepção de Winnicott sobre a agressividade infantil, abordando suas raízes e apontando o caráter das manifestações agressivas à medida em que o indivíduo se desenvolve, bem como o modo como o fator destrutivo relaciona-se com o processo de amadurecimento. Para atingir os objetivos propostos, foram realizados, nesta pesquisa de natureza bibliográfica, levantamento e análise de obras de Winnicott. O estudo mostrou que a agressividade, conforme os pressupostos da teoria winnicottiana, não se restringe a uma reação à frustração, sendo entendida como elemento necessário para o transcorrer do processo evolutivo que, quando ocorre de modo saudável, culmina no desenvolvimento de características e capacidades indispensáveis para o bem-estar psíquico e para os relacionamentos interpessoais.

Palavras-chave: Winnicott; psicanálise; agressividade infantil; desenvolvimento emocional; ambiente facilitador.

\section{THE AGGRESSION AS INTRINSIC ELEMENT OF EMOTIONAL DEVELOPMENT IN WINNNICOTT'S THEORY}

\begin{abstract}
This article concerns Winnicott's concept of infantile aggression, addressing root causes. The nature of aggressive manifestations while the individual is developing, as well as how this destructive influence relates to the maturing process, is discussed. A bibliographical survey and analysis of Winnicott's work was carried out to achieve the proposed objectives. Conforming to Winnicott's theoretical assumptions, the study shows that aggression is not solely a reaction to frustration but should be understood as a necessary part of the course of the evolutionary process which, when it takes place in a healthy way, results in the development of characteristics and capabilities vital for psychological well-being and interpersonal relationships.
\end{abstract}

Keywords: Winnicott; psychoanalysis; infantile aggression; emotional development; facilitating environment

\section{INTRODUÇÃO}

A agressividade infantil é algo muito comum entre as crianças e traz preocupação para a família e para a escola. Esse fenômeno, entretanto, é bastante complexo, bem como é controversa a forma de se lidar com ele. O tema da agressividade infantil ganhou relevância nos últimos anos e tem sido objeto de muitas pesquisas em todo o mundo.

A teoria psicanalítica de Winnicott traz diversas contribuições para a elucidação da agressividade, compreendendo-a enquanto elemento constitutivo da natureza humana, que propicia conquistas no desenvolvimento do sujeito, quando esse se encontra apoiado por um ambiente estável, que favoreça o estabelecimento de vínculos afetivos.

0 presente artigo aborda aspectos da concepção de Winnicott em relação à agressividade infantil, sobretudo nos estágios iniciais do desenvolvimento da criança, apontando o caráter das manifestações agressivas à medida em que ela se desenvolve. Para tanto, realizou-se um estudo bibliográfico da teoria winnicottiana, no qual se efetuou uma investigação acerca das raízes da agressividade e o modo como o fator destrutivo relaciona-se com o processo de amadurecimento. 
Assim, a pesquisa tem como objetivo geral investigar as raízes da agressividade infantil e a sua influência no desenvolvimento emocional, segundo as contribuições de Winnicott - um dos principais autores da psicanálise que investigaram o desenvolvimento infantil.

\section{METODOLOGIA}

Para atingir os objetivos propostos, foram realizados, nesta pesquisa de natureza bibliográfica, levantamento das obras de Winnicott que apresentam contribuições importantes ao tema, bem como análise dessas contribuições.

\section{RESULTADOS}

Winnicott (2005b, p. 102) considera a agressividade algo inerente à constituição do ser humano, possuindo dois significados: "Por um lado, constitui, direta ou indiretamente, uma reação à frustração. Por outro lado, é uma das muitas fontes de energia de um indivíduo." A agressividade, nos primórdios da vida, está associada ao movimento corporal que o bebê realiza ainda no ventre da mãe, possuindo a função de estabelecer o eu (self) e o não-eu. Assim,

Podemos compreender que essas primeiras pancadas infantis levam a uma descoberta do mundo que não é o eu da criança e ao começo de uma relação com objetos externos. $O$ que muito em breve será um comportamento agressivo não passa, portanto, no início, de um simples impulso que desencadeia um movimento e aos primeiros passos de uma exploração. A agressão está ligada, desta maneira, ao estabelecimento de uma distinção clara entre o que é e o que não é o eu. (WINNICOTT, 2008, p. 264)

Se analisarmos os primórdios do desenvolvimento infantil, encontraremos uma estreita relação entre $o$ amor primitivo e os impulsos destrutivos, pelo fato de os desejos do ID nunca serem satisfeitos plenamente.

Segundo Winnicott (2008), o cuidado físico é a primeira forma de amor que o bebê consegue reconhecer e é a partir dele que os alicerces para a saúde mental serão firmados. Em suas obras, Winnicott utiliza o termo mãe suficientemente boa para se referir à mãe que se adapta quase perfeitamente às necessidades do bebê em seu período inicial. Para o autor, é por meio dessa adaptação da mãe que o bebê tem a ilusão de possuir domínio sobre os objetos externos. Dessa forma, os cuidados maternos propiciam a constituição de um mundo que atende aos desejos e às expectativas da criança.

Conforme Winnicott (2008), nessa etapa do desenvolvimento emocional, a mãe ainda não é vista pela criança como um objeto independente dela, e sua agressividade está fortemente ligada ao próprio ato de sobrevivência e alimentação, ou seja, aos impulsos implacáveis (ruthless), embora não haja intenção de destruir.

Quando a criança está excitada, ela realiza um ataque imaginário ao corpo da mãe, por não perceber que se trata do mesmo corpo que valoriza quando está tranquila, "Trata-se da realização do desenvolvimento emocional em que o bebê experimenta pulsões eróticas e agressivas em relação ao mesmo objeto, ao mesmo tempo." (WINNICOTT, 2000, p. 113)

Para o bebê, existiriam duas mães distintas, denominadas por Winnicott (2000) de mãe-objeto e mãe ambiente. A mãe-objeto seria aquela que satisfaz as necessidades urgentes do bebê e é alvo da destruição nos momentos de excitação. Em contrapartida, a mãe-ambiente refere-se àquela que recebe sua afeição e cuida ativamente do bebê, auxiliando no desenvolvimento do sentimento de segurança.

O bebê divide a mãe em duas entidades distintas, que possuem funções também diferentes. Enquanto a mãe-objeto tem a função de sobreviver aos impulsos implacáveis, a mãe ambiente deverá permanecer sensível às necessidades da criança e criar um ambiente acolhedor que receba os atos reparadores e se mostre gratificado.

O autor acredita que esse tipo de agressividade está associado ao amor, sendo assim, a perda da mãe pela criança, nesse estágio, significaria, também, a perda da capacidade de amar e, consequentemente, de se relacionar com os objetos externos.

Winnicott (1975) nos traz uma importante contribuição acerca do valor positivo da destrutividade que ocorre neste ponto do desenvolvimento humano. Para o autor, o 
desenvolvimento envolve, primeiramente, a relação de objeto, e, posteriormente, o uso do objeto. Entre esses dois momentos, existe uma das mais difíceis tarefas a serem realizadas pelo sujeito, que é entender o objeto como algo externo e autônomo, não mais como algo submetido ao seu controle onipotente.

A percepção objetiva do objeto só é alcançada pelo sujeito devido à sobrevivência: o sujeito destrói o objeto em sua fantasia e a sobrevivência deste é que lhe confere seu caráter externo. Após este processo, o sujeito se insere no mundo dos relacionamentos interpessoais, podendo agora usar o objeto, já que o uso requer que o objeto seja compreendido como externo e não como resultado da projeção.

Segundo a tese do autor, a mãe tem a função de sobreviver frente aos impulsos destrutivos do bebê, pois a sobrevivência do objeto de amor o capacitará a diferenciar o que é eu do que é não-eu, objetificando a mãe, resignificando o amor e propiciando o surgimento da fantasia. Dessa maneira,

$O$ estudo desse problema envolve um enunciado do valor positivo da destrutividade. Esta, mais a sobrevivência do objeto à destruição, coloca este último fora da área de objetos criados pelos mecanismos psíquicos projetivos do sujeito. Dessa maneira, cria-se um mundo de realidade compartilhada que o sujeito pode usar e que pode retroalimentar a substância diferente-de-mim dentro do sujeito. (WINNICOTT, 1975, p. 131)

Portanto, para Winnicott (1975), a realidade é decorrente do impulso destrutivo, o que traz implicações na teoria das raízes da agressividade.

A partir do momento em que a criança se integra, ela começará a se preocupar com a mãe, pois perceberá que esta é um ser humano total, que existe independentemente de sua vontade e entenderá o caráter implacável dos impulsos primitivos. Ao reconhecer os elementos destrutivos que acompanham as ideias excitadas primitivas, surge um sentimento de culpa intolerável e a integração garante à criança o controle dos seus impulsos instintivos.

Nessa etapa do desenvolvimento, a criança tende a reparar o mal que imagina ter causado ao seu objeto de amor. Winnicott denomina essa fase de Concern, termo que está ligado ao sentimento de preocupação. Assim, "A preocupação com o objeto amado surge a partir dos elementos agressivos, destrutivos e vorazes no impulso primitivo de amor, que é gradualmente assimilado ao self como um todo [...]" (WINNICOTT, 1990, p. 99). Surge a capacidade de sentir culpa e responsabilizar-se pelo outro, que constituem uma importante conquista no desenvolvimento emocional.

A oportunidade de reparação faz com que a culpa deixe de ser sentida e permaneça latente, reaparecendo apenas quando não há possibilidade de reparação. Os atos reparadores permitem que o bebê liberte sua vida instintual, através da realização de ricas experiências instintivas, amparadas pelo cuidado materno.

Tais conquistas só se tornam possíveis devido ao processo descrito, que ocorre gradualmente, denominado por Winnicott (1990) de Círculo Benigno, cujo estabelecimento está ligado diretamente à continuidade do relacionamento entre o bebê e a mãe.

Dessa forma, o sentimento de confiança na figura materna e a oportunidade de reparação, possibilita que a culpa transforme-se no que Winnicott (2005b) denomina de envolvimento. Tal sentimento é considerado pelo autor como uma reação positiva que permite o reconhecimento e a aceitação da responsabilidade sobre a agressividade, denotando o alcance de um estágio complexo e sofisticado do desenvolvimento emocional. Portanto, a capacidade de envolver-se está atrelada ao desenvolvimento saudável e constitui a base do brincar construtivo e do trabalho.

De acordo com Winnicott (2008), são as experiências satisfatórias de amamentação e as gratificações decorrentes dos bons cuidados maternos que contribuem para que a criança integre a imagem da mãe e, consequentemente, adquira a capacidade de envolvimento e passe a se responsabilizar pelo aspecto agressivo de sua natureza.

Conforme Winnicott (2005b), o desenvolvimento emocional saudável torna o sujeito apto a utilizar seus impulsos instintivos, dentre os quais estão os impulsos agressivos, e convertê-los em uma fonte de energia, que seria 
a base para atividades como o brincar e 0 trabalho.

A aceitação dos símbolos pela criança, de acordo com o autor, é uma marca do desenvolvimento sadio, pois esses possibilitam que ela encontre uma excelente ferramenta que Ihe permite a elaboração de conflitos internos.

O brincar constitui uma das alternativas baseadas na aceitação de símbolos, representa uma prática saudável e essencial para o desenvolvimento emocional da criança, pelo fato de permitir que ela entre em contato com seu mundo interno, de forma a melhor compreendêlo e elaborá-lo, bem como de ampliar sua criatividade e seu self.

Winnicott (2005b) considera que a capacidade de construir apresenta-se para a criança como uma forma importante para lidar com sua agressividade. O brincar construtivo significa um sinal de saúde, pois "[...] em condições ambientais favoráveis, um impulso construtivo está relacionado com a aceitação pessoal, por parte da criança, da responsabilidade pelo aspecto destrutivo da sua natureza." (WINNICOTT, 2005b, p. 107). Esse brincar construtivo surge gradualmente no decorrer do desenvolvimento da criança, já que depende das experiências de vida no ambiente.

$\mathrm{O}$ autor considera que o sonhar constitui outra alternativa madura para o comportamento agressivo, pelo fato de permitir que a criança experimente a destruição na fantasia, acompanhada de um grau de excitação no corpo, o que confere à atividade onírica a característica de uma experiência concreta, não apenas intelectual. Os jogos de competição realizados por crianças e adolescentes também constituem uma opção para o controle da agressividade madura.

A questão da administração do potencial agressivo envolve inúmeros fatores e nem sempre haverá recursos proporcionados pela agressividade madura, aqui encontram-se os casos de crianças que, por motivos diversos, não estão conseguindo gerenciar a contento seus aspectos destrutivos. O presente artigo não versará sobre tais casos por não se tratar do foco de estudo.

Como se pode perceber, o desenvolvimento emocional é algo complexo e a maioria das dificuldades na infância pode não ser detectada por um observador desavisado, já que estas concentram-se, em grande parte, no mundo interno da criança.

\section{DISCUSSÃO}

O estudo mostrou que a agressividade, conforme Winnicott, não se restringe apenas como reação à frustração. Para o autor, a agressividade é inata, sendo, portanto, inerente à natureza humana, estando relacionada, no princípio, ao amor primitivo e à motilidade.

Winnicott nos mostra o valor positivo do aspecto agressivo, que proporciona a constituição da realidade externa, assim como a capacidade de preocupar-se com o outro e buscar a reparação.

Conforme o autor, seriam os fatores ambientais que influenciariam na maneira pela qual o sujeito irá lidar com suas tendências destrutivas. Quando o desenvolvimento emocional progride de forma saudável, apoiado por um ambiente que proporcione cuidados satisfatórios e forneça a possibilidade de reconhecer e manifestar o aspecto destrutivo, a agressividade torna-se madura e converte-se em uma fonte de energia, que será canalizada para atividades como o brincar e o trabalho.

Ao tratarmos de crianças, devemos considerar a complexidade que a vida representa para elas, que precisam desde o princípio lidar com necessidades, sentimentos e impulsos extremamente fortes para seu ego ainda fraco.

Assim, é importante encará-las como seres humanos totais, que, como qualquer outro, precisa elaborar técnicas para lidar e canalizar seus potenciais agressivos.

É fundamental que os cuidadores da criança tenham consciência de que "É tudo muito complicado e é necessário muito tempo para que a criança domine idéias e excitações agressivas e seja capaz de controlá-las sem perder a capacidade para ser agressivo em momentos apropriados, seja ao odiar ou ao amar." (WINNICOTT, 2005b, p. 108)

\section{CONCLUSÃO}

Discutiu-se, por meio deste trabalho, os aspectos destrutivos presentes na natureza humana e a forma como estes podem promover um desenvolvimento emocional saudável, aliados à fatores ambientais favoráveis.

A teoria winnicottiana considera a agressividade parte constitutiva do ser humano e elemento necessário para o transcorrer do processo evolutivo que, quando ocorre de modo saudável, culmina no desenvolvimento de características e capacidades indispensáveis para 
o bem-estar psíquico e para os relacionamentos interpessoais.

Quando o desenvolvimento emocional é apoiado por um ambiente suficientemente bom, os impulsos destrutivos convertem-se em uma força valiosa, que constitui a base de atividades como o trabalho e o brincar, a partir da qual o desenvolvimento pessoal pode se enriquecer, sem que se perca a capacidade para se tornar agressivo nos momentos adequados.

\section{REFERÊNCIAS}

WINNICOTT, D. W. A criança e o seu mundo. 6.ed. Rio de Janeiro: LTC., 2008.

\section{A família e o desenvolvimento}

individual. 3. ed. São Paulo: Martins Fontes, 2005a.

Conversando com os pais. 2. ed. São Paulo: Martins Fontes, 1999.

Da pediatria à psicanálise: obras escolhidas. Rio de Janeiro: Imago, 2000.

. O brincar e a realidade. Rio de Janeiro: Imago, 1975.

. Os bebês e suas mães. 3. ed. São Paulo:

Martins Fontes, 2006.

- Natureza Humana. Rio de Janeiro:

Imago, 1990.

Privação e delinqüência. 4. ed. São

Paulo: Martins Fontes, 2005b.

Recebido para publicação em 17/08/2016

Revisado em 19/08/2016

Aceito em 17/09/2016 